\title{
PELATIHAN PEMANFAATAN MEDIA SOSIAL UNTUK PROMOSI USAHA ATAU BISNIS BAGI SISWA
}

\author{
Ratna Dumilah, Ading Sunarto, Ahyani, Dede Solihin, Hira Maulida \\ Program Studi Manajemen \\ Universitas Pamulang \\ dosen02209@unpam.ac.id
}

\begin{abstract}
The purpose of this community service event is to improve the thinking skills of students or citizens learning at PKBM Negeri 26 Bintaro in utilizing social media for business promotion. The method in carrying out community service activities used is brainstorming and discussion. Techniques in the implementation of community service activities used are group work with the number of participants 21 (twenty one) students or residents learning class $X$ (ten) and class XI (eleven) in PKBM Negeri 26 Bintaro. The output of this community service activity is in the form of a scientific article published through the Pamulang University PKM Dedication Journal, as well as an increase in the knowledge, understanding and skills of students or residents learning at PKBM 26 Bintaro on the use of social media for business promotion.
\end{abstract}

Keywords: PKBM, Social Media, Business Promotion (Business).

\begin{abstract}
Abstrak
Tujuan pada kegiatan pengadian kepada masyarakat ini adalah untuk meningkatkan keterampilan berfikir siswa atau warga belajar di PKBM Negeri 26 Bintaro dalam memanfaatkan media sosial untuk promosi usaha atau bisnis. Metode dalam pelaksanaan kegiatan pengabdian kepada masyarakat yang digunakan adalah curah pendapat dan diskusi. Teknik dalam pelaksanaan kegiatan pengabdian kepada masyarakat yang digunakan adalah kerja kelompok dengan jumlah peserta 21 (dua puluh satu) siswa atau warga belajar kelas X (sepuluh) dan kelas XI (sebelas) di PKBM Negeri 26 Bintaro. Adapun luaran dari kegiatan pengabdian kepada masyarakat ini berupa satu artikel ilmiah yang dipublikasikan melalui Jurnal Dedikasi PKM Universitas Pamulang, serta peningkatan pengetahuan, pemahaman dan keterampilan siswa atau warga belajar di PKBM Negeri 26 Bintaro tentang pemanfaatan media sosial untuk promosi usaha atau bisnis.
\end{abstract}

Kata Kunci : PKBM, Media sosial, Promosi Usaha (Bisnis). 


\section{A. PENDAHULUAN}

Sekolah merupakan bagian dari kehidupan, namun tidak setiap orang menikmatinya. Sebagian anak didik, pada sekolah tertentu tidak bisa menjadikannya sebagai bagian dari nafas kehidupan; sebagian malah berusaha dihindari. Jika demikian, tentunya ada sesuatu yang tidak beres bagi anak didik itu sendiri atau bagi lembaga itu sendiri. Di PKBM inilah mereka yang hampir putus asa dengan sekolah, akhirnya mereka bisa menemukan kembali jalan untuk meniti masa depan.

Upaya dunia pendidikan dalam berpartisipasi membangun bangsa cukup berat tantangannya karena hampir semua pemuda harapan bangsa ini mampir di lembaga pendidikan untuk menjalani proses pendidikan. Apalagi di pendidikan nonformal seperti PKBM Negeri 26 Bintaro yang muridnya banyak dari limpahan pendidikan formal. Tantangannya sama dengan sekolah formal yaitu bagaimana melahirkan pemuda yang religius, berakhlak mulia, cinta bangsanya, cinta lingkungan, anti korupsi, dan anti narkoba. Dua tantangan ini menjadi PR besar bagi dunia pendidikan dalam menempa para pemuda agar berpengetahuan, berkompentensi dalam keterampilan dan memiliki akhlak yang baik.

Menurut Zubaidah (2019) lembaga PKBM khususnya PKBM Negeri 26 Bintaro perlu adanya upaya pendampingan kepada para pemuda yang ikut dalam pembelajaran di program kesetaraan. Tantangan besar adalah mereka kebanyakan anak putus sekolah, di mana banyak sekali pelanggaran di sekolah formal yang kemudian berakhir dikembalikan kepada orang tuanya. Akhirnya PKBM sebagai pilihan terakhir untuk melanjutkan pendidikan menengahnya. Di sinilah beratnya peran PKBM dalam mengembalikan mereka ke jalur yang benar sebagaimana pelajar lainnya. Apalagi kehidupan religius baik keluarga maupun individunya kurang mendukung. Dan PKBM bukanlah tempat menempa sikap dan perilaku religus. Di sinilah perlunya para guru PKBM untuk terus memberikan pendampingan dan memotivasi akan peran dan fungsi pemuda di dalam beragama, agar masa tua dan masa di hari kemudian menjadi tersadarkan untuk kembali ke jalur yang benar.

PKBM Negeri 26 Bintaro Jakarta Selatan adalah pusat kegiatan belajar masyarakat yang sama dengan semua PKBM pada umumnya, dimana didalamnya memiliki tujuan untuk memberdayakan dan meningkatkan kualitas hidup masyarakat baik dari segi sosial maupun segi ekonomi agar masyarakat dapat hidup mandiri. PKBM Negeri 26 Bintaro terletak di Jl. Bintaro Permai III/No. 3B Kecamatan Pesanggrahan Kotamadya Jakarta Selatan dengan Kode Pos 12330 dan memiliki nomor telepon 0217371108. Berdasarkan pada upaya dan tenaga yang dimiliki oleh PKBM tersebut dapat dilihat bahwa kegiatan atau program program upaya yang dilakukan oleh PKBM Negeri 26 Bintaro dimulai dari kursus dan pendidikan kesetaraan, dimana kegiatan tersebut dilaksanakan oleh warga belajar pada hari Senin s/d Jum'at pukul $08.00 \mathrm{~s} / \mathrm{d}$ 15.15. Kegiatan atau program tersebut dilakukan dengan maksud untuk memberikan manfaat yang sebaik - baiknya pada seluruh masyarakat yang berada di sekitar lingkungan PKBM Negeri 26 Bintaro Jakarta Selatan.

Permasalahan yang dihadapi adalah masih banyak siswa atau warga belajar di PKBM Negeri 26 Bintaro yang belum paham dalam memanfaatkan media sosial untuk usaha promosi atau bisnis, hal ini mendorong para guru atau tutor di PKBM Negeri 26 Jakarta terus berupaya keras untuk memberikan kesempatan bagi siswa PKBM Negeri 26 Bintaro guna meningkatkan pengetahuan dan keterampilan agar memiliki pengetahuan diluar pendidikan 
kesetaraan seperti pengetahuan tentang pemanfaatan media sosial untuk usaha promosi atau bisnis.

Pada saat ini, sistem penjualan produk secara elektronik sedang berkembang amat pesat. Banyak terdapat perusahan mulai dari usaha skala kecil, menengah, sampai perusahaan internasional banyak yang menggunakan dan memanfaatkan teknologi tersebut sebagai salah satu strategi dalam upaya untuk memasarkan produk atau jasa yang ditawarkan. Banyak sekali perusahaan-perusahaan yang melakukan promosi lewat media sosial. Mereka menjadikan sistem penjualan online sebagai sarana promosi yang murah, murah, efektif dan terjangkau. Dengan keuntungan tersebut perusahaan akan mendapatkan dampak yang besar lewat promosi dalam media sosial. Produk-produk yang ditawarkan secara online jugalah sangat beragam.

Sedangkan seperti yang diketahui, belakangan ini sedang marak di Indonesia, khususnya di kota-kota besar seperti di Jakarta bisnis online shopping, Sejak awal tahun 2012, sudah mulai banyak dilakukannya penjualan online melalui instagram, facebook, dan twitter. Semua kegiatan yang berhubungan dengan penjualan kini dapat dilakukan melalui instagram, facebook, dan twitter. Baik itu dari mulai mencari calon pembeli sampai dengan menawarkan atau mempromosikan produk yang akan dijual nantinya. Dengan memanfaatkan media sosial tersebut, para pelaku bisnis ini dapat menjalin komunikasi dengan para pembeli maupun dengan para calon pembeli, sehingga para pelaku bisnis online ini akan dapat menjangkau calon pembeli yang lebih banyak lagi tanpa adanya batasan ataupun hambatan yang berarti dengan menggunakan media sosial instagram.

Sekarang ini memang banyak peluang usaha baru bermunculan dan menelurkan banyak wirausahawan baru di Indonesia. Tidak hanya pengusaha berskala besar tapi juga pengusaha kecil dan menengah, bahkan usaha kecil menengah saat ini mengalami pertumbuhan yang sangat pesat. Munculnya berbagai peluang usaha dengan modal kecil membuat orang untuk mencoba membangun usahanya sendiri. Cukup banyak pengusaha kecil menengah tidak hanya membuka toko yang ada fisiknya, tetapi toko virtual di internet yang dapat menjangkau orang lebih banyak lagi. Bahkan beberapa pengusaha online yang saya kenal memiliki penghasilan yang sangat fantastis. Para siswa atau warga belajar di PKBM Negeri 26 Bintaro diajarkan tentang cara memilih peluang usaha dengan modal kecil dan peluang usaha bisnis online dari rumah dan diharapkan bisa memilih peluang usaha dengan modal kecil serta bisa menjalankan bisnisnya secara online.

Banyak calon pengusaha memutuskan untuk mundur ketika menemukan kendala saat memulai sebuah bisnis, padahal peluang usaha yang menjanjikan itu sudah ada di depan mata. Masalah klasik yang sering kita dengar adalah kurangnya modal awal untuk memulai bisnis mereka. Solusinya adalah memilih peluang usaha dengan modal kecil yang memang sudah terbukti menguntungkan. Dan seperti apakah usaha dengan modal kecil yang terbukti menguntungkan?

Demi terwujudnya para pemuda yang berpengetahuan, berkompentensi dalam keterampilan dan memiliki akhlak yang baik dan berdasarkan analisis situasi tersebut diatas, pengusul bersama mitra sepakat mengusung tema "Pelatihan Pemanfaatan Media Sosial Untuk Promosi Usaha Atau Bisnis Bagi Siswa". Tentunya dengan bimbingan para pendamping guru atau tutor di PKBM Negeri 26 Bintaro, semoga para siswa atau peserta 
didik di PKBM Negeri 26 Bintaro dapat menemukan peluang usaha yang bisa dijadikan pijakan di masa setelah lulus nanti.

\section{B. METODE PELAKSANAAN KEGIATAN}

Metode kegiatan pengabdian kepada masyarakat yang digunakan adalah curah pendapat, diskusi dan kerja kelompok. Adapun susunan kegiatannya adalah sebagai berikut:

\section{Pembukaan}

$\begin{array}{ll}\text { MC \& Moderator } & \text { : Dwi Septiawan } \\ \text { Pembukaan } & \text { : Ratna Dumilah, S.E., M.M } \\ \text { Sambutan } & \text { : Wawan Gunawan, S.E. } \\ \text { Paparan Materi } & \text { : Ading Sunarto, S.E., M.M. } \\ \text { Sesi I Tanggal 10 Oktober } 2019 \\ \begin{array}{ll}\text { Instruktur } & \text { : Dede Solihin, S.E., M.M. } \\ \text { Kegiatan } & \text { : 1) Curah Pendapat } \\ & \text { 2) Diskusi } \\ & \text { 3) Kerja kelompok }\end{array}\end{array}$

Tema Kegiatan : Bisnis Afiliasi (Affiliate Marketing) dan Bisnis Denga Membuat Toko Online (Online Shop).

\section{Sesi II Tanggal 11 Oktober 2019}

Instruktur

: Ahyani, S.E., M.M.

Kegiatan

: 1) Curah Pendapat

2) Diskusi

3) Kerja kelompok

Tema Kegiatan : Bisnis Online Dengan Membangun Blog/ Website Portal

\section{Sesi III Tanggal 12 Oktober 2019}

Instruktur

: Hira Maulida, S.E., M.M.

Kegiatan

: 1) Curah Pendapat

2) Diskusi

3) Kerja kelompok

Tema Kegiatan : Cara Membuat Facebook Ads dan Cara Membuat Instagram Ads.

\section{HASIL DAN PEMBAHASAN}

Berdasarkan wawancara, tanya jawab dan pengamatan langsung selama kegiatan berlangsung, kegiatan pengabdian pada masyarakat ini memberikan hasil sebagai berikut:

1. Meningkatnya pengetahuan dan pemahaman siswa atau warga belajar tentang pemanfaatan media sosial untuk promosi usaha atau bisnis.

2. Meningkatnya keterampilan siswa atau warga belajar di PKBM Negeri 26 Bintaro tentang pemanfaatan media sosial untuk promosi usaha atau bisnis.

Beberapa faktor yang mendukung terlaksananya kegiatan pengabdian pada masyarakat ini adalah kerjasama yang baik dari para guru atau tutor selama kegiatan, sehingga kegiatan 
berlangsung dengan lancar dan efektif. Sedangkan faktor penghambatnya adalah kurang antusiasnya siswa atau warga belajar, keterbatasan waktu pelatihan dan fasilitas peralatan yang minim. Berikut materi pelatihan pemanfaatan media sosial untuk promosi usaha atau bisnis yang diberikan dalam kegiatan pengabdian masayarakat di PKBM Negeri 26 Bintaro ;

\section{SESI I}

\section{Bisnis Afiliasi (Affiliate Marketing)}

Ini adalah model bisnis yang sangat banyak dijalankan oleh internet marketer baik di luar negeri maupun di dalam negeri. Untuk menjalankan bisnis afiliasi, kita tidak harus memiliki produk, tapi kita bisa menjual produk orang lain melalui internet, baik itu melalui blog, social media, email marketing, dan lain-lain. Kita mendapatkan komisi sekian persen dari total harga barang yang dijual. Produk yang dijual pun bermacam, ada produk berbentuk fisik, berbentuk digital, dan juga berbentuk membership. Keunikan dari bisnis afiliasi ini adalah, kita tidak perlu repot mengurus hal-hal yang berhubungan dengan pembuatan produk, packing produk, dan pengiriman produk. Kita hanya perlu mempromosikan link khusus yang didapatkan dari vendor (pemilik produk). Jika link tersebut di-klik oleh seseorang dan orang tersebut melakukan pembelian dari link affiliate milik kita, maka kita akan mendapatkan komisi. Untuk program afiliasi lokal yang direkomendasikan adalah;

a. Produk Fisik
1) Lazada.com
2) Bhineka.com
3) Blibli.com

b. Produk Digital

1) Ratakan.com Marketplace

2) Idaff.com Affiliate Marketplace

2. Bisnis Dengan Membuat Toko Online (Online Shop)

Memiliki sebuah toko online saat ini sudah sangat mudah. Bisnis online shop bisa dijalankan oleh orang yang memiliki toko offline dan ingin meningkatkan penjualan dengan cara menjual secara online. Dan bisnis ini juga bisa dikerjakan oleh orang yang tidak memiliki produk, yaitu dengan cara bergabung dengan supplier atau produsen yang menawarkan sistem dropship atau reseller. Untuk memulai bisnis online shop tentunya Anda harus punya toko online. Sebenarnya tidak sulit untuk membuat toko online, tutorialnya bisa kita dapatkan di internet. Setelah lanjutnya adalah mencari produsen produk atau mitra kerjasama yang memberikan layanan reseller atau dropship. Setelah diterima menjadi mitra, kita bisa mulai memposting produk di toko online dan mempromosikan toko online tersebut. Ada beberapa produsen yang direkomendasikan untuk diajak kerjasama;
a. Cakning.com
b. Suplier.id
c. Komisian.com
d. Dropshipaja.com 


\section{SESI II}

\section{Bisnis Online Dengan Membangun Blog/ Website Portal}

Membangun blog/website bisa menjadi salah satu model bisnis yang sangat menjanjikan untuk jangka panjang. Semakin meningkatnya pengguna internet dan smartphone menjadi indikator bahwa media blog/ website ke depannya akan semakin banyak trafik, tentunya sesuai dengan niche blog/ website yang dibangun. Inilah yang bisa kita jadikan peluang bisnis dengan modal kecil. Coba perhatikan halaman website yang linknya sering bertebaran di Facebook dan Google (misalnya Merdeka.com, Kompas.com, Alodokter.com, Viralnova.com, Cerpen.co.id, dan lain-lain) di dalam halaman website itu kita bisa melihat adanya iklan Google Adsense. Kebanyakan blog dan website portal ini memonetize websitenya dengan program PPC (pay per click), khususnya Google Adsense.

Program PPC ini sangat cocok untuk mereka yang memiliki web atau blog dengan trafik pengunjung yang tinggi. Salah satu model bisnis jaringan iklan adalah dengan mengikuti program PPC (pay per click) seperti Google Adsense, Bidvertiser, Kliksaya, Kumpulbloger, dan lain-lain. Selain iklan PPC, model bisnis iklan yang lain adalah iklan mandiri, yaitu dengan cara menawarkan space iklan pada blog Anda dengan harga yang sudah ditentukan.

Penghasilan dari blog/ website yang memasang iklan PPC maupun iklan mandiri tidak bisa dianggap remeh lho. Banyak sekali blogger dan pemilik website yang mendulang uang dari iklan di blognya, mulai dari puluhan juta rupiah, ratusan juta rupiah, hingga miliaran rupiah. Salah satu blogger yang memiliki penghasilan fantastis dari blognya adalah Linda Ikeji. Blogger asal Nigeria ini diperkirakan mendapatkan milliaran rupiah per bulan dari blognya.

\section{SESI III}

1. Cara Membuat Facebook Ads

Berikut adalah langkah-langkah yang harus kamu lakukan bila kalau ingin memasang iklan lewat Facebook Ads!
a. Login ke Facebook Ads
b. Mulai Promosikan Iklan
c. Persiapkan Materi Iklan
d. Lakukan Pembayaran

2. Cara Membuat Instagram Ads

a. Buka Facebook Ads Manager

b. Pilih Pembuatan Iklan Terpandu

c. Tentukan Tujuan Iklan

Selanjutnya, tentukan tujuan iklan yang ingin Anda capai. Facebook Ads Manager menyediakan tujuan iklan dalam tiga kategori berbeda, yaitu Kesadaran, Pertimbangan, dan Konversi.

1) Kesadaran Kesadaran Merek:

2) Pertimbangan (Consideration) Lalu lintas/Trafik

3) Konversi (Conversion)

Konversi: Untuk Anda yang ingin meningkatkan jumlah orang yang berbelanja dengan melakukan pembelian produk pada website Anda. Penjualan katalog produk: 
Menampilkan iklan mengenai produk katalog Anda sesuai dengan target yang ditentukan. Kunjungan toko: Jika Anda memiliki toko offline atau toko fisik, silakan pilih bagian ini untuk meningkatkan pelanggan mengunjungi toko Anda

a) Klik Tujuan Iklan Anda

b) Pilih Jenis Iklan

Di jenis iklan Uji Split, Anda akan diminta membuat dua iklan dengan yang mirip, yaitu konten A dan konten B. Target audience Anda akan dibagi menjadi dua dan akan melihat iklan yang berbeda. Dengan begitu Anda bisa melihat konten iklan mana yang lebih menarik lebih banyak trafik. Sayangnya, jenis iklan uji split membutuhkan dana dua kali lipat dibandingkan jenis pengoptimalan anggaran. Di tutorial ini saya memilih jenis iklan kedua karena lebih cocok untuk pemula. Pada langkah ini Anda juga perlu menentukan anggaran iklan. Anda bebas menentukan anggaran iklan Anda di Facebook Ads. Di tutorial ini kami memasukkan anggaran sebesar 1 juta rupiah.

1. Tulis Nama Iklan dan Pilih Tujuan Trafik

2. Tampilkan Promo

3. Tentukan Target Audience

Seperti yang saya sebutkan di awal artikel, Anda bisa menentukan spesifikasi target audience Anda berdasarkan faktor di bawah ini:

a. Pemirsa Khusus

b. Lokasi

c. Umur

d. Jenis Kelamin

e. Bahasa

f. Penargetan Terperinci

g. Koneksi

h. Tentukan Penempatan

i. Pilih Jadwal

j. Hubungkan dengan Akun Instagram

Dilangkah ini yang perlu Anda lakukan adalah menambahkan akun Instagram yang ingin Anda hubungkan dengan halaman Facebook Anda. Sebaiknya Anda tambahkan akun Instagram khusus untuk mempromosikan bisnis Anda.

1) Klik Tambahkan sebuah Akun

2) Pilih Format Iklan

Terdapat lima jenis format iklan yang dapat Anda pilih, yaitu sebagai berikut ini:

a) Karosel: Tampilan iklan dengan 2 atau lebih gambar atau video yang dapat digeser.

b) Gambar Tunggal: Tampilan iklan dengan 1 gambar.

c) Video Tunggal: Iklan dengan sebuah video.

d) Tayangan Slide: Iklan dengan gambar atau video slide hingga 10 gambar.

e) Koleksi: Iklan dapat berupa gabungan gambar dan video.

Pada tutorial ini kami memilih Format Karosel dengan gambar yang dapat digeser.

3) Buat Teks

4) Pilih Gambar, Tulis Judul, dan Masukkan Tautan 
5) Lakukan Pembayaran

\section{KESIMPULAN DAN SARAN}

Dari kegiatan pengabdian pada masyarakat ini dapat disimpulkan bahwa:

1. Pengetahuan dan pemahaman siswa atau warga belajar PKBM Negeri 26 Bintaro menjadi meningkat

2. Keterampilan siswa atau warga belajar dalam pemanfaatan media sosial untuk promosi usaha atau bisnis semakin meningkat.

Mengingat besarnya manfaat kegiatan pengabdian pada masyarakat ini, maka selanjutnya perlu:

1. Mengadakan sosialisasi dan pelatihan serupa pada siswa atau warga belajar di PKBM lain.

2. Adanya kesinambungan program pasca kegiatan pengabdian ini sehingga para siswa atau warga belajar benar-benar dapat mempraktekan pelatihan pemanfaatan media sosial untuk promosi usaha atau bisnis.

\section{DAFTAR PUSTAKA}

Alma, B. (2014), Manajemen Pemasaran dan Pemasaran Jasa, Alfabeta, Bandung.

Depdiknas. (2006). Kurikulum Tingkat Satuan Pendidikan (KTSP). Jakarta: Depdiknas.

Kotler, P., \& Amstrong, G. (2016), Prinsip-prinsip Pemasaran. Edisi 13. Jilid 1, Erlangga, Jakarta.

Rambat, L. (2013), Manajemen Pemasaran Jasa Berbasis Kompetensi. (Edisi 3). Salemba Empat, Jakarta.

Rangkuti, F. (2014). Analisis SWOT Teknik Membedah Kasus Bisnis. Jakarta: Gramedia Pustaka Utama.

Resyaningrum, D., \& Muhlasin, N. (2019). Bimbingan Karir Remaja Putus Sekolah di Pusat Kegiatan Belajar Masyarakat (PKBM) Bunga Kantil Jebres Surakarta, eprints.iainsurakarta.ac.id.

Rulli, N. (2017), Media Sosial : Perspektif Komunikasi, Budaya, dan Sosioteknologi, Bandung : Remaja Rosdakarya.

Shirky, C. (2008). Here Comes Everybody. USA: Penguin Group.

Sihombing, U., \& Gutama. (2000). Profil Pusat Kegiatan Belajar Masyarakat (PKBM) di Indonesia pada Masa Perintisan. Jakarta: PD. Mahkota.

Solihin, D. (2020), Faktor-Faktor Yang Mempengaruhi Kinerja Pemasaran Pada PT Prima Ufuk Semesta (Studi Empiris Pada Outlet Rekanan Pt. Prima Ufuk Semesta Di Wilayah Jabodetabek), Jurnal Semarak, Vol. 3. No. 1.

Solihin, D. (2020), Pengaruh Kualitas Pelayanan, Harga, Dan Promosi Terhadap Keputusan Pelanggan Dalam Memilih Klub Basket Satria Indonesia Tangerang Selatan, Jurnal Pemasaran Kompetitif, Vol. 3, No. 3. 